\title{
NOTE
}

\section{A comparative experimental study on gas generation from saturated and aromatic hydrocarbons isolated from a Cambrian oil in Tarim basin}

\author{
Hui Tian,,${ }^{1 *}$ Xianming XiaO, ${ }^{1}$ Huajun Gan,${ }^{2}$ Liguo Yang, ${ }^{1}$ Liguo Guo ${ }^{1}$ and Jiagui Shen ${ }^{1}$ \\ ${ }^{1}$ State Key Laboratory of Organic Geochemistry, Guangzhou Institute of Geochemistry, Chinese Academy of Sciences, \\ Guangzhou 510640, China \\ ${ }^{2}$ Department of Coal and Coalbed Methane Engineering, Faculty of Earth Resources, China University of Geosciences, \\ Wuhan 430074, China
}

(Received February 16, 2009; Accepted July 14, 2009)

\begin{abstract}
The saturated and aromatic hydrocarbons isolated from a Cambrian oil (TZ62well) in the central Tarim basin were pyrolyzed in sealed gold tubes to investigate how the gases generated from them would vary in compositions of constituents and their carbon isotopes. The results illustrates that the gases from the cracking of saturates are much drier and more enriched in ${ }^{12} \mathrm{C}$ than the gases from the cracking of aromatics at the same levels of thermal maturity. The dryness index of the gases (defined as the volume percentage of $\mathrm{C}_{1}$ to $\mathrm{C}_{1-5}$ ) from the cracking of saturates ranges from $26.2 \%$ to $90.6 \%$ whereas it is never lower than $60.6 \%$ for the gases from the cracking of aromatics throughout the experiment. The methane from the saturates shows a larger carbon isotope change, ranging from $-54.8 \%$ to $-35.5 \%$, than the methane from the aromatics whose carbon isotopes range from $-37.4 \%$ to $-32.2 \%$ o throughout the experiment. The above experimental observations indicate that the cracking of crude oils with different bulk compositions could produce gases that have distinct constituents and carbon isotopic compositions.
\end{abstract}

Keywords: oil cracking, saturates, aromatics, pyrolysis experiment, natural gas, carbon isotopes

\section{INTRODUCTION}

The crude oil generated by the thermal transformation of sedimentary organic matter can be further cracked to form hydrocarbon gases and pyrobitumen at more severe thermal stress (Tissot et al., 1987). The accumulation of gases associated with oil cracking has been well documented in many basins (Prinzhofer and Huc, 1995; Lewan, 2002; Isaken, 2004; Zhao et al., 2005; Ma et al., 2007; Tian et al., 2007; Mancini et al., 2008). Numerous experiments have been performed on crude oils to investigate their thermal stability and cracking mechanisms (Ungerer et al., 1988; Behar et al., 1991; Horsfield et al., 1992; Pepper and Dodd, 1995; Schenk et al., 1997; Tsuzuki et al., 1999; Huang and Otten, 2001; Hill et al., 2003; Tang et al., 2005). However, crude oil is a complex mixture of various compounds that can be classified into saturates, aromatics, resins and asphaltens. The bulk composition of crude oil may vary significantly due to source rock types, maturity and genetic and/or post genetic proc-

\footnotetext{
*Corresponding author (e-mail: tianhui@gig.ac.cn)

Copyright (@ 2010 by The Geochemical Society of Japan.
}

esses, such as biodegradation and migration fractionation. Therefore, the general observations of oil cracking obtained from the pyrolysis of whole oil samples can not be reliably extrapolated to all geological conditions when the bulk composition of crude oil varies significantly in different basins.

In recent years, many authors have conducted a series of pyrolysis experiments on various compounds, including aromatics (Behar et al., 1999; Lorant et al., 2000; Darouich et al., 2006a, b), saturates (Jackson et al., 1995; Behar and Vandenbrouck, 1996; Burnham et al., 1997; McKinney et al., 1998; Zhang et al., 2008) and even NSO compounds (Behar et al., 2008), to investigate their individual thermal stability and gas potentials. Based on the results of model compounds, Vandenbrouck et al. (1999) attempted to use a compositional kinetic model to simulate petroleum formation and cracking in the North Sea. More recently, Behar et al. (2008) presented a more detailed compositional kinetic model of oil cracking based on extensive pyrolysis data on crude oil. However, most of the aforementioned studies are focused on the thermal stability of various compounds, and little attention has been paid to the chemical, especially the carbon isotopic compositions of the generated gases. In the present study, 
we pyrolyzed the saturated and aromatic hydrocarbons isolated from a Cambrian oil from the Tarim basin in order to illustrate how the resulting generated gases would vary in constituent and their carbon isotopic compositions. The resulting experimental observations may be helpful for understanding the chemical compositions of gases from the secondary cracking of crude oil.

\section{SAMPLES AND METHODS}

\section{Sample preparation}

A crude oil sample was collected from the Silurian reservoirs of well TZ62 in the central Tarim basin. The biomarkers in the crude oil show its Cambrian origin (Xiao et al., 2005). The crude oil was first treated with approximately 40 -fold volumes of $n$-hexane for $24 \mathrm{hr}$ to precipitate the asphaltenes. Then, the saturated and aromatic hydrocarbons were isolated from deasphaltened crude oils by using column chromatography as described in Fowler et al., (1995). Briefly, a clean and dried glass column (50 cm in length and $15 \mathrm{~mm}$ internal diameter) was packed sequently with pre-activated alumina (80-200 mesh) and silica gel (80-200 mesh) (3:1, w/w). During the packing the column was constantly tapped by a rubber stick to ensure that the alumina and silica gel are compacted tightly. The deasphaltened crude oil was introduced into the top of the column to produce a concentrated band (Bastow et al., 1998). n-Hexane and $n$-Hexane/ dichloromethane $(1: 1, v / v)$ were then used to elute saturated and aromatic hydrocarbons, respectively.

\section{Pyrolysis experiment}

The pyrolysis experiments were conducted in sealed gold tubes using a method described widely in the literatures (Hill et al., 2003; Tang et al., 2005; Pan et al., 2006; Zhang et al., 2008). In summary, an appropriate amount of sample (approximate 80-15 mg from low temperature to high temperature) was injected into a number of gold tubes (40 $\mathrm{mm}$ in length, $3 \mathrm{~mm}$ internal diameter and 0.2 $\mathrm{mm}$ in wall thickness) that were pre-welded at one end. Once loaded, the open end of each gold tube was purged with argon gas to displace the air in the tube before being pressed in a vise to create an initial seal, which was subsequently welded in an atmosphere of argon gas. The sealed gold tubes were then loaded into the stainless steel pressure vessels that were connected together to maintain a uniform pressure among them. The final pressure was adjusted and maintained at $50 \mathrm{MPa}$ by pumping water in or out of vessels during the experiment. The temperature, measured by a thermocouple placed within an empty vessel with an accuracy of $\pm 1^{\circ} \mathrm{C}$, was first raised from the room temperature to $250^{\circ} \mathrm{C}$ within $12 \mathrm{~h}$ and then programmed to $600^{\circ} \mathrm{C}$ at a heating rate of $20^{\circ} \mathrm{C} / \mathrm{h}$. During the experiments the pressure error was $\pm 1 \mathrm{MPa}$.

\section{Gas chemistry and stable carbon isotope analysis}

Before chemical analysis, every gold tube was cleaned using dichloromethane solvent and placed into a vacuum collector interfaced to a HP 5890 II gas chromatograph. The gold tube was pierced by a steel needle attached to the vacuum collector into which the gas was released. After $30 \mathrm{~s}$ equilibration time, the valve was switched to channel the gas into the gas chromatograph. The gaseous hydrocarbons $\left(\mathrm{C}_{1-5}\right)$ were quantified using an external standard. The GC employed a Poraplot Q capillary column $(30 \mathrm{~m} \times 0.25 \mathrm{~mm} \times 0.25 \mu \mathrm{m})$ and helium as carrier gas. The oven temperature for the hydrocarbon gas analysis was initially held at $70^{\circ} \mathrm{C}$ for $6 \mathrm{~min}$, ramped from 70 to $130^{\circ} \mathrm{C}$ at $15^{\circ} \mathrm{C} / \mathrm{min}$, from 130 to $180^{\circ} \mathrm{C}$ at $25^{\circ} \mathrm{C} / \mathrm{min}$, and then held at $180^{\circ} \mathrm{C}$ for $4 \mathrm{~min}$.

The carbon isotope compositions of hydrocarbon gases were measured on a Delta Plus XL gas chromatographisotope ratio mass spectrometer (GC-IRMS). The GC was equipped with a Poraplot Q capillary column $(30 \mathrm{~m} \times 0.32$ $\mathrm{mm} \times 0.25 \mu \mathrm{m})$. Helium was used as carrier gas. The samples were injected at an initial temperature of $50^{\circ} \mathrm{C}$ (held for $3 \mathrm{~min}$ ), after which the oven was heated to $190^{\circ} \mathrm{C}$ at a rate of $15^{\circ} \mathrm{C} / \mathrm{min}$ and held for $15 \mathrm{~min}$. The carbon isotope ratios for individual gaseous hydrocarbons were calculated using $\mathrm{CO}_{2}$ as a reference gas that was automatically introduced into the IRMS at the beginning and end of each analysis. The carbon isotopic value of $\mathrm{CO}_{2}$ reference gas was calibrated by NBS 22 oil as a reference material using element analysis (ThermoQuest Flash EA1112 Series), combined with isotope ratio mass spectrum (Delta Plus $\mathrm{XL}$ ). In addition, a standard mixture of gaseous hydrocarbons $\left(\mathrm{C}_{1}-\mathrm{C}_{4}\right)$, with known isotope compositions calibrated by our laboratory, was used daily to test the performance of the instrument. At least two measurements were performed for each gas sample to confirm the analytical errors were less than \pm 0.3 (\%o, PDB).

\section{Bulk stable carbon isotope analysis}

The bulk carbon isotopes of saturates and aromatics were measured on a ThermoQuest Flash EA1112 Series C N elemental analyzer linked to a Finnigan Delta Plus XL Isotope Ratio Mass Spectrometer (IRMS) via a Finnigan MAT ConFlo III unit. The samples were combusted under a flow of helium and oxygen in an oxidation tube at $900^{\circ} \mathrm{C}$ and the element of carbon was converted $\mathrm{CO}_{2}$ gas that was introduced into IRMS for measurement. The $\mathrm{CO}_{2}$ reference gas was calibrated against NBS 22 oil standard and a working standard (black carbon) was measured prior to, during and after each batch of samples to monitor the accuracy of measurement with the EA-IRMS system. 


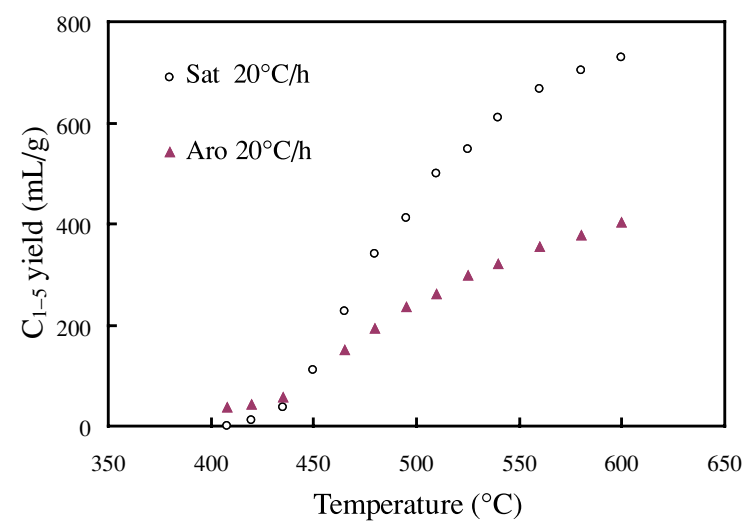

Fig. 1. A plot showing the total hydrocarbon gas yields from the pyrolysis of saturated and aromatic hydrocarbons at a heating rate of $20^{\circ} \mathrm{C} / \mathrm{h}$.

\section{RESULTS AND DISCUSSIONS}

\section{Gas yield}

The constituent and their carbon isotopic compositions of gases generated by the pyrolyis of saturated and aromatic hydrocarbons are listed in Table 1 . The aromatics produce larger quantities of hydrocarbon gases than the saturates at temperatures of $435^{\circ} \mathrm{C}(R o=1.22 \%)$ or lower, after which the quantity of $\mathrm{C}_{1-5}$ gases from the cracking of saturates is far higher than that of the aromatics (Fig. 1). At the maximum temperature of $600^{\circ} \mathrm{C}(R o=3.88 \%)$ the yield of $\mathrm{C}_{1-5}$ gases from the cracking of saturates is $729 \mathrm{~mL} / \mathrm{g}$ whereas the yield from the cracking of aromatics is only $401 \mathrm{~mL} / \mathrm{g}$ (Fig. 1). The gas potential for saturates is nearly two times higher than that of the aromatics because the saturates are more enriched in hydrogen than the aromatics. During the pyrolysis experiment, the yield of methane increases continuously with temperature due to its extremely high thermal stability (Fig. 2a). This indicates that the methane can be obtained as a stable product. However, the wet gases $\left(\mathrm{C}_{2}-\mathrm{C}_{5}\right)$ reach their maximum yield, and then, they are cracked at more severe thermal stress (Figs. 2b-d). This illustrates that the wet gases $\left(\mathrm{C}_{2}-\mathrm{C}_{5}\right)$ are intermediate products whose yields are controlled by their relative rates of generation and cracking in a closed system. Their yields will continue to increase and reach a maximum value at the temperature where the generation and cracking rates balance, after which the yields will be observed to decline due to the predominance of cracking over generation. In the present study, the balance temperatures for ethane and propane are approximately $525^{\circ} \mathrm{C}(R o=2.56 \%)$ and $495^{\circ} \mathrm{C}(R o=$ $2.04 \%$ ), respectively (Table 1, Fig. 2).

\section{Constituents in gases}

The experimental pyrolysis of crude oil in a closed

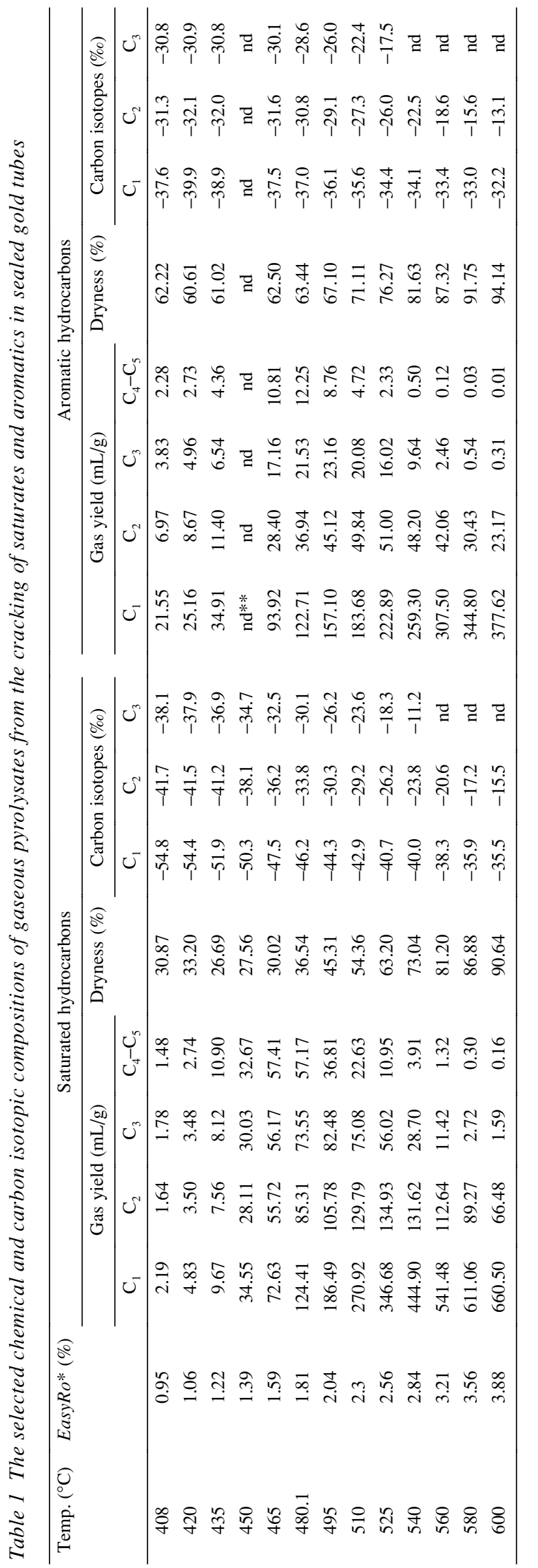

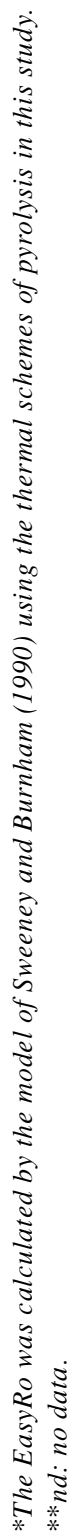



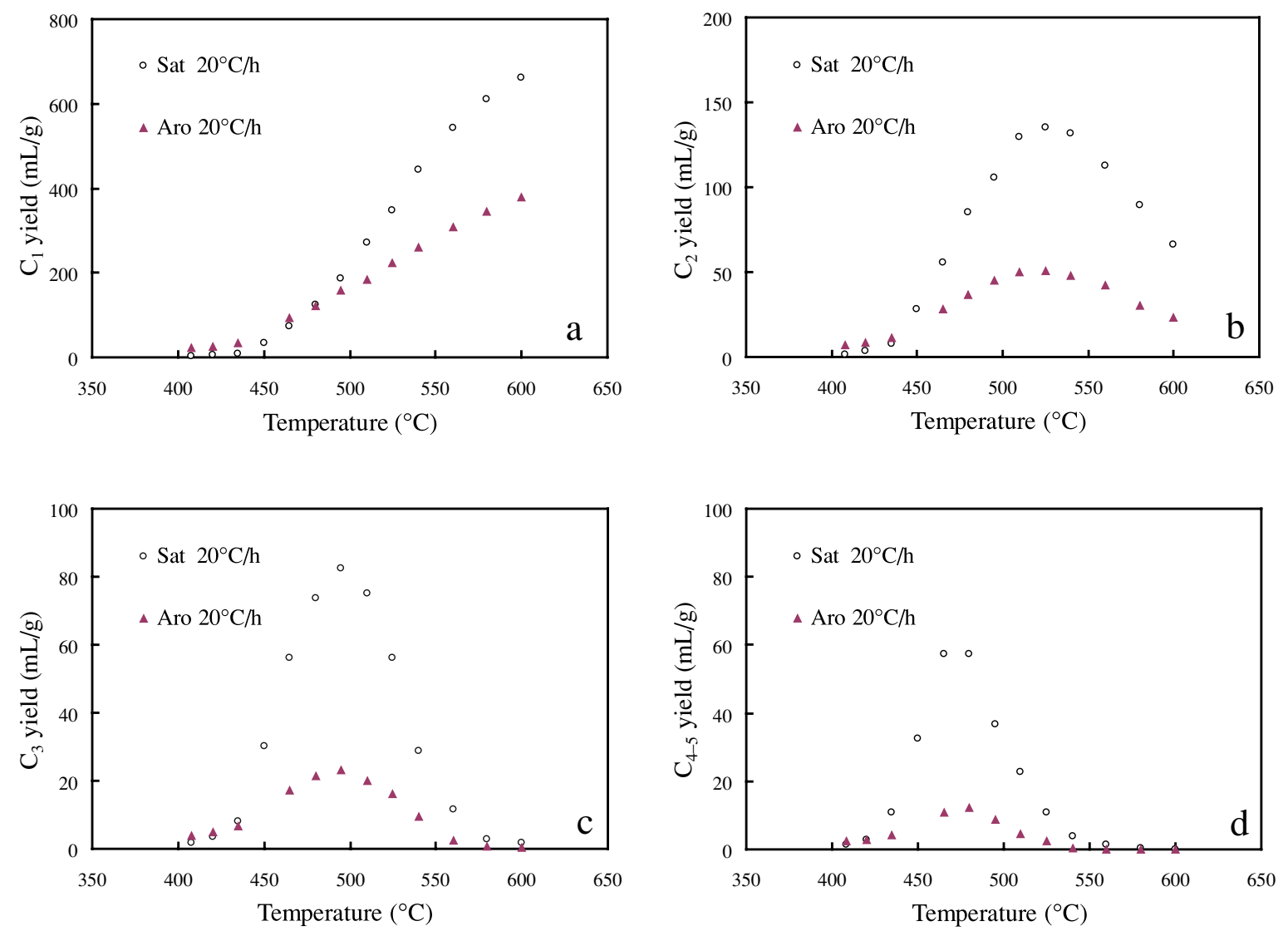

Fig. 2. Plots showing the yields of methane, ethane, propane and $C_{4-5}$ component from the pyrolysis of saturated and aromatic hydrocarbons at a heating rate of $20^{\circ} \mathrm{C} / \mathrm{h}$.

system produces gases dominated by $\mathrm{C}_{2-5}$ wet gases while the natural gas usually contains more than $60 \%$ methane (Mango, 2001; Hill et al., 2003). Several mechanisms have been suggested to explain this inconsistency, including catalytic intervention (Mango and Hightower, 1997), gas fractionation during expulsion (Inan, 2000), fractionation during migration (Price and Schoell, 1995, Snowdon, 2001) and accumulation efficiency (Michels et al., 2002). Others have proposed specific precursors to methane, including methyl naphthalenes (van Aarssen et al., 1999) and phenanthrenes (McNeil and BeMent, 1996). The present study shows that the chemical composition of gases depends significantly on the precursors of gases. Before appreciable cracking of ethane and propane, the gases evolved from the saturates are dominated by the wet gases and the gas dryness (defined as the volume percentage of $\mathrm{C}_{1}$ to $\mathrm{C}_{1}-\mathrm{C}_{5}$ ) is as low as $26.7 \%$ at $435^{\circ} \mathrm{C}$ (Fig. 3). With the cracking of wet gases the methane gradually becomes dominant and the dryness reaches a value of $90.6 \%$ at $600^{\circ} \mathrm{C}$. These observations are consistent with those obtained from the pyrolysis of single saturated compounds at similar conditions (Jackson et al.,
1995; Zhang et al., 2008). However, the situation is quite different for the gases from the aromatics (Fig. 3), where gas dryness never lower than $60 \%$ during the experiments. The largest differences in dryness for the gases from the saturates and aromatics is up to $35 \%$ at a temperature of $435^{\circ} \mathrm{C}(R o=1.22 \%)$.

This result illustrates that the chemical composition of gases from oil cracking is partly controlled by the bulk composition of crude oils. The high concentration of methane for gases from aromatics can be partly explained by the demethylation reactions that occur widely in aromatics and high maturity source rocks (McNeil and BeMent, 1996; Behar et al., 1999, 2002; Lorant et al., 2000; Darouich et al., 2006a). For example, the alkylaromatics cleave preferentially under thermal stress at the position between the first $(\alpha)$ and second carbon $(\beta)$ atoms as shown in Fig. 4. The products would then be $-\mathrm{CH} 2$. (the black dot shows a free radical), attached to the aromatic system, and a chain radical $\mathrm{R} \cdot$, one carbon shorter than the original chain. The R·, being in a highly aromatic atmosphere, would be expected to migrate to another aromatic system, where it would become attached, 


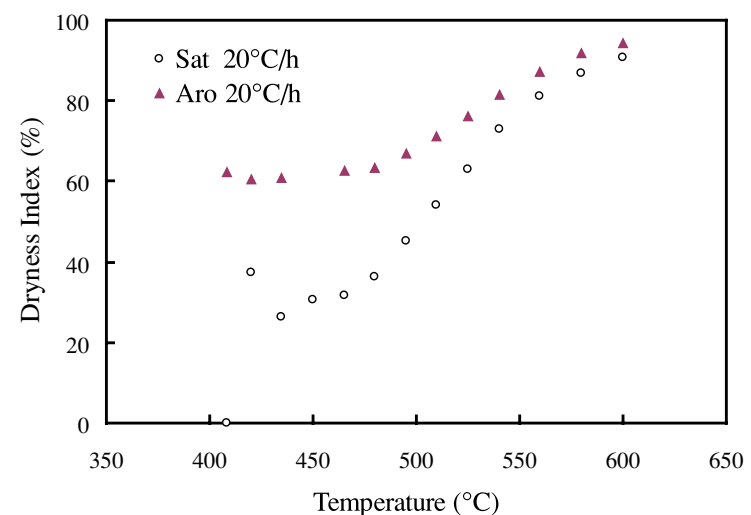

Fig. 3. The changes in gas Dryness with increasing thermal stress for the two different samples.
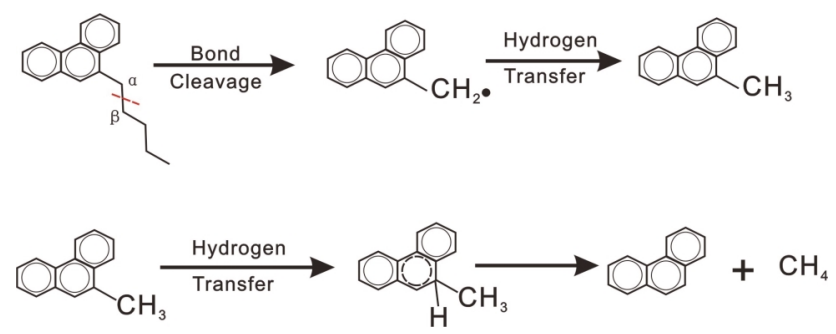

Fig. 4. Sketch reactions illustrating the formation of methane from demythylation of alkyl-aromatics (modified from McNeil and BeMent, 1996 and see details in Smith and Savage, 1992).

making another alkyl-on-aromatic structure and liberating a hydrogen atom. The - $\mathrm{CH} 2 \cdot$ could acquire the liberated hydrogen atom, or it could abstract a hydrogen atom from any alkyl group in the vicinity. The result would be a methyl group attached to an aromatic system. Then, the methyl-aromatics lose the methyl groups to produce methane by a series of hydrogen transfer reactions (Fig. 4) (Smith and Savage, 1992; McNeil and BeMent, 1996). However, the gas generation from saturates are mainly related to the progressive cracking of high molecular weight saturates to low molecular weight saturates and the direct formation of methane by demethylation from a long, straight carbon chain is minor (Jackson et al., 1995; McKinney et al., 1998; Behar and Vandenbroucke, 1996; Hill et al., 2003).

\section{Carbon isotopes}

The bulk carbon isotopic compositions $\left(\delta^{13} \mathrm{C}\right)$ of saturates and aromatics are measured to be $-28.6 \%$ and $-28.3 \%$ respectively and those values of methane, ethane and propane from the pyrolysis of saturates and aromatics are listed in Table 1 and compared in Fig. 5. For the methane evolved from the saturates, the lightest $\delta^{13} \mathrm{C}$
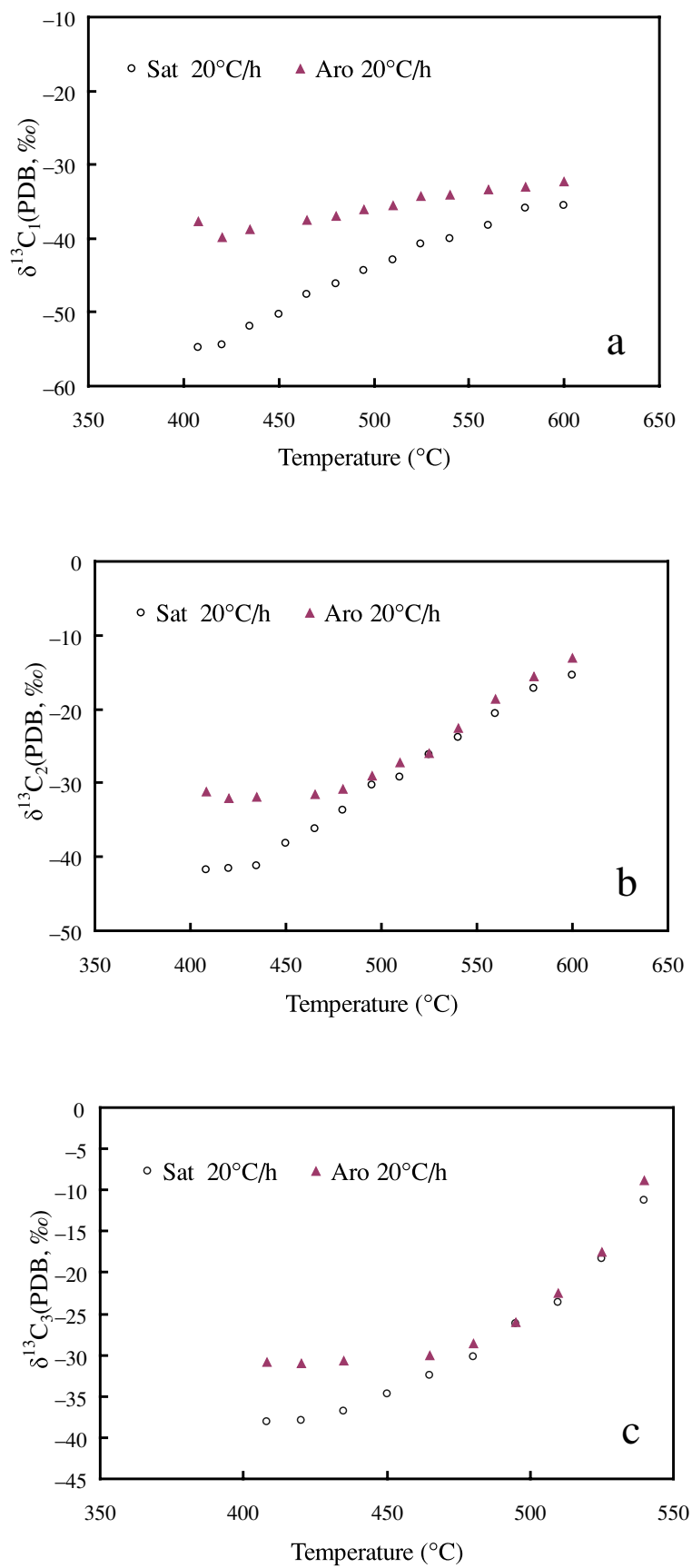

Fig. 5. Plots showing the changes in methane carbon isotope compositions with temperature for the gases from the two different samples pyrolyzed at $20^{\circ} \mathrm{C} / \mathrm{h}$.

measured is $-54.8 \% o$ at $408^{\circ} \mathrm{C}(R o=0.95 \%)$ and the heaviest value of $-35.5 \%$ occurs at $600^{\circ} \mathrm{C}(R o=3.88 \%)(\mathrm{Ta}-$ ble 1, Fig. 5a). The carbon isotopic change observed during the pyrolysis experiment is $19.3 \%$. The methane from the aromatics, however, shows a smaller carbon isotopic change with $\delta^{13} \mathrm{C}$ ranging from the lightest value of $-39.9 \%$ o to the heaviest value of $-32.2 \%$ (Table 1, Fig. 


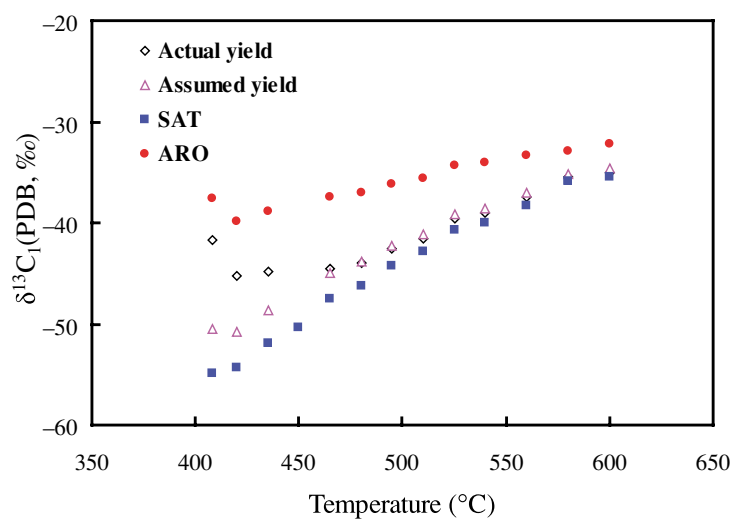

Fig. 6. A plot showing how the mixing of methane derived from saturates and aromatics results in a carbon isotope reversal during the early stage of thermal maturity. The Actual yield and Assumed yield denote that the carbon isotope of mixed methane was calculated based on the actual and assumed yields of methane from saturates and aromatics, respectively See details in text.

5a). Generally, the methane from the saturates is more enriched in ${ }^{12} \mathrm{C}$ than the methane from the aromatics at the same thermal stress levels. The largest difference of $18.4 \%$ occurs at $408^{\circ} \mathrm{C}(R o=0.95 \%)$, after which the difference becomes smaller with increasing thermal stress. At the temperature of $600^{\circ} \mathrm{C}$, the difference is about $3.3 \%$ (Fig. 5a).

Paralleling the methane $\delta^{13} \mathrm{C}$, both ethane and propane from the aromatics are more enriched in ${ }^{13} \mathrm{C}$ than those from the saturates at the same thermal maturity levels (Figs. 5b and 5c). At lower temperatures the differences in $\delta^{13} \mathrm{C}$ are larger than at the higher temperatures. For example the difference in ethane $\delta^{13} \mathrm{C}$ between the two samples is about $10.5 \%$ at $408^{\circ} \mathrm{C}(R o=0.95 \%)$. With increasing temperature the differences become smaller and nearly negligible (less than $0.48-2.4$ per mil) as the maturity approaches $2.5 \%$ Ro for ethane and $2 \% R o$ for propane (Fig. 5b). It is worth noting that the $\delta^{13} \mathrm{C}$ of ethane and propane for both samples become extremely enriched in ${ }^{13} \mathrm{C}$ with respect to their initial $\delta^{13} \mathrm{C}$ when they begin to crack (Table 1, Figs. 5b and 5c). They are finally heavier than the saturate and aromatic fractions of the starting oil at maturity around $2.2 \%$ Ro for saturate and $2 \%$ Ro for aromatics. This trend also was reported by other authors (Lorant et al., 1998; Zhang et al., 2008). In some cases this also occurs in sedimentary basins. For example, James (1983) suggested that the relatively heavy $\delta^{13} \mathrm{C}$ values of ethane and propane in the Delaware-Val Verde basin were probably caused by secondary cracking. More recently, Tilley and Muehlenbachs (2006) reported the cracking of ethane and propane in the Gething Formation in the western Canadian sedimentary basin. The residual gases have unusually heavy $\delta^{13} \mathrm{C}$ values $\left(\delta^{13} \mathrm{C}_{[1]}=-34 \%\right.$, $\delta^{13} \mathrm{C}_{[2]}=$ $-13 \%$, and $\delta^{13} \mathrm{C}_{[3]}=0 \%$ ). Therefore the $\delta^{13} \mathrm{C}$ values of ethane and propane could be used to determine the maximum thermal stress they have experienced.

It is well accepted that the gases thermally derived from organic matters usually become enriched in ${ }^{13} \mathrm{C}$ with increasing thermal maturity. In many pyrolysis experiments, however, an obvious reversal in the carbon isotopes of gaseous hydrocarbons often occurs at the early stage of methane generation (Lorant et al., 1998; Tang et al., 2000; Cramer et al., 2001; Hill et al., 2003; Tian et al., 2007). This indicates that the carbon isotope of methane first become enriched in ${ }^{12} \mathrm{C}$ and then in ${ }^{13} \mathrm{C}$ with increasing thermal maturities. One explanation for this phenomenon is hypothesizing two or more precursors for gas generation with different isotopic compositions (Smith et al., 1985; Tang and Jenden, 1998). Our experimental results support this hypothesis. The $\delta^{13} \mathrm{C}$ value of methane from aromatics has a reversal of $2.3 \%$ between $408^{\circ} \mathrm{C}$ and $420^{\circ} \mathrm{C}$, while that of methane from saturates shows no reversal in the present experimental conditions. When the methane from saturates and aromatics are mixed at a ratio of 3:1 (i.e., methane produced by 3 pieces of saturates and 1 pieces of aromatics), the reversal in methane carbon isotope becomes more obvious, with a difference of $3.5 \%$ between $408^{\circ} \mathrm{C}$ and $420^{\circ} \mathrm{C}$ (Fig. 6). This indicates that even if there is no reversal in the $\delta^{13} \mathrm{C}$ of methane from aromatics and saturates, the mixing of methane from saturates and aromatics might result in a reversal in methane $\delta^{13} \mathrm{C}$ values. This can be explained by the fact that the methane yield from aromatics is much higher than that from saturates in early stages of maturation (Table 1 and Fig. 2). If we assume that both the saturates and aromatics produce the same quantity of methane at the same levels of thermal maturity, the mixing of methane at a ratio of 3:1 would only lead to a minor reversal of $0.2 \%$ in $\delta^{13} \mathrm{C}$ values (Fig. 6). This illustrates that the reversal in methane $\delta^{13} \mathrm{C}$ is controlled not only by the carbon isotope difference of distinct gases, but also their difference in yields. Therefore, the actual carbon isotope reversal with thermal maturity in geological conditions could vary significantly due to variations in precursors of gases and their gas potentials.

\section{Conclusions}

The pyrolysis of satrurates and aromatics isolated from a Cambrian oil illustrates that the gases from the cracking of saturates are much drier and more enriched in ${ }^{12} \mathrm{C}$ than the gases from the cracking of aromatics at equivalent thermal maturity levels. The dryness of the gases from the cracking of saturates ranges from $26.2 \%$ to $90.6 \%$ whereas it is never lower than $60.6 \%$ for the gases from the cracking of aromatics during the whole experiment. 
The methane evolved from the saturated hydrocarbons shows a larger carbon isotope variation, ranging from $-54.8 \%$ to $-35.5 \%$, than the methane from the aromatics whose carbon isotopes range from $-39.9 \%$ to $-32.2 \%$ throughout the experiment. The maximum difference in methane carbon isotope composition between the two gases is up to $17.2 \%$ at the lowest pyrolysis temperature and this difference becomes smaller with increasing temperatures (only $3.3 \%$ at the temperature of $600^{\circ} \mathrm{C}$ ). Our pyrolysis observations indicate that the cracking of crude oils can be one of the most crucial reactions for the generation of gases, in which the constituents and carbon isotope compositions are clearly different.

Acknowledgments-The authors thanks Prof. Liu Jinzhong, associate Prof. $\mathrm{Xu}$ An and Chen Huashan for their help with the pyrolysis experiments and chemical and stable isotopic analysis. This study was financially supported by the National Natural Science Fund of China (Grant No. 40802025), the Key Project of Chinese Academy of Sciences (Grant No. KZCX2YW-Q05-03-01) and the National Natural Science Fund for Distinguished Young Scholars (Grant No. 40625011). We thank Drs. Daniel Dawson, Yoshito Chikaraishi and an anonymous reviewer for their insightful comments and suggestions, which significantly improved the manuscript. Especially we thank the GJ associate editor Ken Sawada and the reviewer Daniel Dawson, who helped much during the English revisions. This is contribution No. IS-1096GIGCAS.

\section{REFERENCES}

Bastow, T. P., Alexander, R., Sosrowidjojo, I. B. and Kagi, R. I. (1998) Pentamethylnaphthalenes and related compounds in sedimentary organic matter. Org. Geochem. 28, 585-595.

Behar, F. and Vandenbroucke, M. (1996) Experimental determination of the rate constants of the $n-\mathrm{C}_{25}$ thermal cracking at 120, 400, and 800 bars: Implications for high pressure/high-temperature prospects. Energy \& Fuels 10, 932940.

Behar, F., Ungerer, P., Kressman, S. and Rudkiewicz, J. L. (1991) Thermal evolution of crude oils in sedimentary basins: experimental simulation in a confined system and kinetic modeling. Revue de l'Institut Francais du petrole 46, 151-181.

Behar, F., Budzinski, H., Vandenbrouke, M. and Tang, Y. (1999) Methane generation from oil cracking: kinetics of 9methlphenanthrene cracking and comparison with other pure compounds and oil fractions. Energy \& Fuel 13, 471-481.

Behar, F., Lorant, F., Budzinski, H. and Desavis, E. (2002) Thermal stability of alkylaromatics in natural systems: kinetics of thermal decomposition of dodecylbenzene. Energy \& Fuel 16, 831-841.

Behar, F., Lorant, F. and Mazeas, L. (2008) Elaboration of a new compositional kinetic schema for oil cracking. Org. Geochem. 39, 764-782.

Burnham, A. K., Gregg, H. R., Ward, R. L., Knauss, K. G., Copenhaver, S. A., Reynolds, J. G. and Sanborn, R. (1997)
Decomposition kinetics and mechanism of $n$-hexadecane$1,2-{ }^{13} \mathrm{C}_{2}$ and dodec-1-ene-1,2- ${ }^{13} \mathrm{C}_{2}$ doped in petroleum and n-hexadecane. Geochim. Cosmochim. Acta 61, 3725-3737.

Cramer, B., Faber, E., Gerling, P. and Krooss, B. M. (2001) Reaction kinetics of stable carbon isotopes in natural gas: insights from dry, open system pyrolysis experiments. Energy \& Fuels 15, 517-532.

Darouich, T. Al., Behar, F. and Largeau, C. (2006a) Thermal cracking of the light aromatic fraction of Safaniya crude oil-experimental study and compositional modelling of molecular classes. Org. Geochem. 37, 1130-1154.

Darouich, T. Al., Behar, F. and Largeau, C. (2006b) Pressure effect on the thermal cracking of the light aromatic oilImplications for deep prospects. Org. Geochem. 37, 11551169.

Fowler, M. G., Hamblin, A. P., Hawkins, D., Stasiuk, L. D. and Knight, I. (1995) Petroleum geochemistry and hydrocarbon potential of Cambrian and Ordovician rocks of western Newfoundland. Bull. Can. Petrol. Geol. 43, 187-213.

Hill, R. H., Tang, Y. and Kaplan, I. R. (2003) Insights into oil cracking based on laboratory experiments. Org. Geochem. 34, 1651-1672.

Horsfield, B., Schenk, H. J., Mills, N. and Welte, D. H. (1992) Closed-system programmed-temperature pyrolysis for simulating the conversion of oil to gas in a deep petroleum reservoir. Org. Geochem. 19, 191-204.

Huang, W. L. and Otten, G. A. (2001) Cracking kinetics of crude oil and alkanes determined by diamond anvil cell-fluorescence spectroscopy pyrolysis: technique development and preliminary results. Org. Geochem. 32, 817-830.

Inan, S. (2000) Gaseous hydrocarbons generated during pyrolysis of petroleum source rocks using unconventional grainsize: implications for natural gas composition. Org. Geochem. 31, 1409-1418.

Isaksen, G. H. (2004) Central North Sea hydrocarbon system: Generation, migration, entrapment, and thermal degradation of oil and gas. Amer. Assoc. Petrol. Geol. Bull. 88, 1545-1572.

Jackson, K. J., Burnham, A. K., Braun, R. L. and Knauss, K. G. (1995) Temperature and pressure dependence of nhexadecane cracking. Org. Geochem. 23, 941-953.

James, A. T. (1983) Correlation of natural gas by use of carbon isotopic distribution between hydrocarbon components. Amer. Assoc. Petrol. Geol. Bull. 67, 1176-1191.

Lewan, M. (2002) New insight on timing of oil and gas generation in the central Gulf Coast Interior zone based on hydrous-pyrolysis kinetic parameters. Gulf Coast Assoc. Geol. Soc. Transac. 52, 607-620.

Lorant, F., Prinzhofer, A., Behar, F. and Huc, A. Y. (1998) Carbon isotopic and molecular constraints on the formation and the expulsion of thermogenic hydrocarbon gases. Chem. Geol., 147, 249-264.

Lorant, F., Behar, F. and Vandenbroucke, M. (2000) Methane generation from methylated aromatics: kinetic study and carbon isotope modeling. Energy \& Fuels 14, 1143-1155.

Ma, Y., Guo, X., Guo, T., Huang, R., Cai, X. and Li, G. (2007) The Puguang gas field: New giant discovery in the mature Sichuan Basin, southwest China. Amer. Assoc. Petrol. Geol. Bull. 91, 627-643. 
Mancini, E. A., Li, P., Goddard, D. A., Ramirez, V. and Talukdar, S. (2008) Mesozoic (upper Jurassic-lower Cretaceous) deep gas reservoir play, central and eastern Gulf coastal plain. Amer. Assoc. Petrol. Geol. Bull. 92, 283-308.

Mango, F. D. (2001) Methane concentrations in natural gas: the genetic implications. Org. Geochem. 32, 1283-1287.

Mango, F. D. and Hightower, H. W. (1997) The catalytic decomposition of petroleum into natural gas. Geochim. Cosmochim. Acta 61, 5347-5350.

McKinney, D. E., Behar, F. and Hatcher, P. G. (1998) Reaction kinetics and $n$-alkane product profiles from the thermal degradation of ${ }^{13} \mathrm{C}$-labeled $n-\mathrm{C}_{25}$ in two dissimilar oils as determined by SIM/GC/MS. Org. Geochem. 29, 119-136.

McNeil, R. I. and BeMent, W. O. (1996) Thermal stability of hydrocarbons: Laboratory criteria and field examples. Energy \& Fuel 10, 60-67.

Michels, R., Enjelvin-Raoult, N., Elie, M., Mansuy, L., Faure, P. and Oudin, J. (2002) Understanding of reservoir gas compositions in a natural case using stepwise semi-open artificial maturation. Mar. Petrol. Geol. 19, 589-599.

Pan, C., Yu, L., Liu, J. and Fu, J. (2006) Chemical and carbon isotopic fractionations of gaseous hydrocarbons during abiogenic oxidation. Earth Planet Sci. Lett. 246, 70-89.

Pepper, A. S. and Dodd, T. A. (1995) Simple kinetic models of petroleum formation. Part II: oil-gas cracking. Mar. Petrol. Geol. 12, 321-340.

Price, L. C. and Schoell, M. (1995) Constraints on the origins of hydrocarbon gas from compositions of gases at their site of origin. Nature 378, 368-371.

Prinzhofer, A. A. and Huc, A. Y. (1995) Genetic and postgenetic molecular and isotopic fractionations in natural gases. Chem. Geol. 126, 281-290.

Schenk, H. J., di Primio, R. and Horsfield, B. (1997) The conversion of oil into gas in petroleum reservoirs. Part 1: Comparative kinetic investigation of gas generation from crude oils of lacustrine, marine and fluviodeltaic origin by programmed-temperature closed-system pyrolysis. Org. Geochem. 26, 467-481.

Smith, C. M. and Savage, P. E. (1992) Reactions of polycyclic alkylaromatics. 4. Hydrogenolysis mechanisms in 1alkylpyrene pyrolysis. Energy \& Fuel 00, 195-202.

Smith, J. W., Rigby, D., Gould, K. W. and Hart, G. (1985) An isotopic study of hydrocarbon generation processes. Org. Geochem. 8, 341-347.

Snowdon, L. R. (2001) Natural gas composition in a geological environment and the implications for the processes of generation and preservation. Org. Geochem. 32, 913-931.

Sweeney, J. J. and Burnham, A. K. (1990) Evaluation of a simple model of vitrinite reflectance based on chemical kinetics. Amer. Assoc. Petrol. Geol. Bull. 74, 1559-1570.
Tang, Y. and Jenden, P. D. (1998) Modeling gas isotopic fractionation during thermogenic gas generation. ABS-PAPACS 215 (Part 1), p. 3-GEOC.

Tang, Y., Perry, J. K., Jenden, P. D. and Schoell, M. (2000) Mathematical modeling of stable carbon isotope ratios in natural gases. Geochim. Cosmochim. Acta 64, 2673-2687.

Tang, Y., Huang, Y., Ellis, G., Wang, Y., Kralert, P. G., Gillaizeau, B., Ma, Q. and Hwang, R. (2005) A kinetic model for thermally induced hydrogen and carbon isotope fractionation of individual $n$-alkanes in crude oil. Geochim. Cosmochim. Acta 69, 4505-4520.

Tian, H., Xiao, X. M., Wilkins, R. W. T., Li, X. Q. and Gan, H. J. (2007) Gas sources of the YN2 Gas Pool in the Tarim Basin-evidence from gas generation and methane carbon isotope fractionation kinetics of source rocks and crude oils. Mar. Petrol. Geol., 24, 29-41.

Tilley, B. and Muehlenbachs, K. (2006) Gas maturity and alteration systematics across the Western Canada Sedimentary Basin from four mud gas isotope depth profiles. Org. Geochem. 37, 1857-1868.

Tissot, B. P., Pelet, R. and Ungerer, P. (1987) Thermal history of sedimentary basins, maturation indices, and kinetics of oil and gas generation. Amer. Assoc. Petrol. Geol. Bull. 71, 1445-1466.

Tsuzuki, N., Takeda, N., Suzuki, M. and Yokoi, K. (1999) The kinetic modeling of oil cracking by hydrothermal pyrolysis experiments. Int. J. Coal Geol. 39, 227-250.

Ungerer, P., Behar, F., Villalba, M., Heum, O. R. and Audibert, A. (1988) Kinetic modelling of oil cracking. Org. Geochem. 13, 857-868.

van Aarssen, D. G. K., Bastow, T. P., Alexander, R. and Kagi, R. I. (1999) Distribution of methylated naphthalenes in crude oils: indicators of maturity, biodegradation and mixing. Org. Geochem. 30, 1213-1227.

Vandenbroucke, M., Behar, F. and Rudkiewicz, J. L. (1999) Kinetic modeling of petroleum formation and cracking: implications from the high pressure/high temperature Elgin Field (UK, North Sea). Org. Geochem. 30, 1105-1125.

Xiao, Z., Lu, Y., Sang, H., Pan, Z. and Li, Y. (2005) A typical Cambrian reservoir: Origin of oil in well TZ62 Silurian reservoirs, Tarim basin. Geochimica 34, 262-273

Zhao, W., Luo, P., Chen, G., Cao, H. and Zhang, B. (2005) Origin and reservoir rock characteristics of dolostones in the early Triassic feixianguan formation, Sichuan Basin, China: significance for future gas exploration. J. Petrol. Geol. 28, 83-100.

Zhang, H., Geng, A., Xiong, Y., Liu, J. and Liu, J. (2008) Closedsystem programmed-temperature pyrolysis on $n$-octadecane: Implications for the conversion of oil to gas. Geochem. J. 42, 403-412. 